\title{
METAL FATIGUE IN THEORY AND DESIGN
}

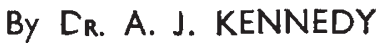 \\ British Iron and Steel Research Association, London, S.W.II
}

\begin{abstract}
A $\mathrm{N}$ international conference on the fatigue of metals, sponsored by the Institution of Mechanical Engineers, in co-operation with the American Society of Mechanical Engineers, was held in London during September 10-14. Some eighty papers were presented, covering the whole range of interests in fatigue, both academic and technological. Contributions were made by authors from Australia, France, Germany, Japan and the U.S.S.R., as well as from the United States and Great Britain. More than six hundred scientists and engineers attended the meetings, and the discussions on the papers brought in contributors from many more countries. The papers are to be read again in New York at a second conference during November 28-30, and the whole of the proceedings, with the discussions from both centres, is to be published afterwards in a single volume. The enterprise is the most ambitious of its kind yet attempted, and occurs at a significant stage in the development of fatigue theory and machine design.
\end{abstract}

The conference covered so wide a range of research that no short report could do justice to the detailed information presented. Certain general observations on the subject can, however, be made, prompted and shaped, as it were, by the discussions which took place. These can be very usefully viewed against the background of past development, and suggest the way in which the subject may evolve in the fitture.

Fatigue in metals, and in solids generally, has been plagued with an inappropriate title and an inaccurate popular press. As a subject it is really quite old. The early observations, being far in advance of understanding of the solid state, gave rise to a terminology, and even a philosophy, which have hampered scientific thinking ever since. Criticisms are repeatedly lavished on the scientists for their failure to communicate ideas and findings in a way which all can understand. This proves a most admirable exercise, but it seems hard that the scientist, who deals with difficult and often esoteric mathematical concepts, should be selected as the plain man's scapegoat, good material though he may be. He might reasonably, at times, ask for a little less plainness at the other end.

In the case of fatigue, however, much of the responsibility for the popular misconceptions rests squarely on the scientific exponents. Intentionally or otherwise, the doubts and dissensions within the subject are popularly interpreted as revealing a general ignorance of its nature, cause and effects. Recent failures in aircraft appeared to give point to this. In fact, there is, in certain directions, a surfeit of information on the subject; test data have been loading down the technical press for years, following the much careful and laborious experiment that has been undertaken in establishing the importance of a variety of practical factors. The general answer to the popular legend that metal fatigue is as prevalent and as little understood as the common cold is supplied by every aircraft, or every engine, which does not fail during its design life. These are the successful products of anti-fatigue methods, for which engineering science should be given every credit. Of course, there is uncertainty about the fundamental nature of fatigue. But the theories of the mechanical properties of metals generally are still very conjec. tural, and it needs to be remembered that the microscopic mechanics of the solid state have turned out to be far more difficult to understand than its chemistry or its metallurgy, in the structural-compositional sense. Problems involving, essentially, the structures of atoms, and the differences between such structures, supremely difficult though these may be, have gone forward more readily than those involving the forces between atoms in aggregates, whether solid or liquid. It was, of course, in order to deal with these difficulties that the idea of a crystal imperfection, or dislocation, was first introduced. While this idea fitted at once certain observations on the nature of slip in single crystals, it is only during very recent times, indeed during the past ten years, that the theory can be said to have established itself as a fruitful study in its own right. It now has a number of successes to its credit, of various kinds; but these are recent and involve fairly simple systems, such as, for example, pure single crystals under restricted conditions of stress and temperature. It is therefore unreasonable to expect that such an involved problem as the behaviour of complex alloys under complex stresses and conditions should be particularly well understood, or even that some single answer exists.

This latter assumption, that all failures under alternating stresses can be lumped together as the consequence of some unique process called fatigue, needs to be strongly dispelled. Useful mechanical metals have a complicated structure, and are subjected to a complicated thermal and stress treatment. They are made up of regions of differing composition, some of which may in turn possess a form of internal substructure. Wach particular type of region, in isolation, may have quite different characteristics of deformation from the others, and the boundaries between such regions are also mechanically very different.

Nor are the internal stresses uniform. On the atomic scale, a number of mechanisms can occur in such aggregates: structural transformations of various types, diffusion, recrystallization, ageing, recovery, slip, polygonization, relative movements of boundaries, and so on. The operation of these mechanisms is frequently markedly directional, that is, a general anisotropy exists. At certain points quite distinctive changes may occur under alternating stresses characterized by an apparent concentration of plastic strain. In some alloys, it is interesting that an actual extrusion of material may occur at the slip band. Ultimately it is possible for small cracks to form at such sites, and some of these will be propagated, possibly to failure.

There are, then, two phases in the development of fatigue. First, the process of crack formation, and secondly that of crack propagation. It can be demonstrated that the crack usually appears at 
points of high local slip; but the development of such a crack must obviously depend in some way upon all the other processes taking place. Frequently all these processes are taken collectively to constitute what is termed fatigue. On the basis of present knowledge, this seems unnecessary and misguided. The fact is that a number of processes occur, and the partition of the stress energy between these depends greatly on such factors as stress, frequency and temperature, on the geometry of the system, and indeed on the chance arrangement of the constituents of the structure. It may be that future research will show that no special or singular mechanisms are required to explain crack formation by fatigue, but only the extension of others already recognized and established. At present the question is an open one. In any event, it will be evident from what has been said that, although we still have to explain how. cracks may be formed in the slip-bands of crystals under alternating stresses, and to account for the differing nature of the local deformation as compared with uni-directional stressing, a number of possible modes of crack formation may arise in a complex alloy, giving rise to cracks at quite different sites under different conditions. Some discipline in our thinking is here much needed, for the idea of some single basic mechanism is deeply rooted. It is strange that this should be so, for we do not attempt to force the observations in other fields, such as those of brittle fracture, creep and ageing, into a single-mechanism explanation.

Once formed, and depending on the stress pattern and the nature of the material, a crack may be propagated. We might again well ask why this final phase should also automatically be brought together under the same general heading of fatigue. Cracks can be introduced in other ways, by quenching for example, and their propagation need have nothing whatever to do with the fatigue process as we imagine it. Some caution is necessary here, because the propagation is itself obviously dependent on the nature of the material traversed by the cracks, and it may be that the development of what might be termed the genuine fatigue process reduces the overall ductility and hence speeds the crack propagation. It is dangerously easy, then, to label all crack-forming processes, such as those that occur during corrosion, as fatigue, and hence to lose the significance that should be attached to the term.

In general, then, it seems that too much has been brought together under the title of fatigue, and that as a consequence the fundamental problem has become obscured. The problem remains, simply, why a fracture can occur in a pure single crystal (that is, in a regular lattice) under alternating stresses of a value which would not lead to failure if applied uni-directionally. The physicists seem reasonably agreed among themselves that dislocation theory can supply the answer. As it stands, the theory is now capable of demonstrating how vacancies may be generated by moving dislocations, and how these vacancies may bring about the observed increase in the speed of recovery from any residual straining. So far as the formation of an incipient crack is concerned, the collection of vacancies into clusters is taken to be the essential operation, and a mechanism for this has been proposed. No one would quarrel greatly with the general dynamics of the process as set out, and it is only fair that the theory should be allowed to prove its points, where relevant, by drawing on results, established elsewhere, of a rather different character. The theory may, in other words, establish a working model before it is fitted up around the fatigue problem, and this is indeed what has happened.

'The engineers, for their part, can scarcely be blamed for being unconvinced by these tactics. Much of the theory they have necessarily to take on trust, and they feel that it is no solution simply to select from the several dislocation and vacancy mechanisms which are theoretically possible the one that best fits the facts. A much more critical experimental approach is required to demonstrate why a certain sequence of events takes place rather than another. To establish this it may be necessary to cast the experimental net much wider, and to bring in other properties, an understanding of which is already more firmly grounded. Electrical properties, particularly under conditions of extreme temperature, may be useful in affording such cross-links and in thus strengthening the whole theoretical structure. Generally, engineering has been little helped in its day-to-day problems by the more fundamental physical research. This is in many ways understandable, once the scale of the difficulties is appreciated. What is much more difficult to justify is the slight statistical treatment which the problem has attracted. Even if causes are difficult to sort out, the effects, whatever they may be, ought to provide plenty of good material for statistical analysis. There has in fact been work on these lines, and very excellent some of it is; but the infiltration of the methods into the design field, and the replacement of outdated design factors, is long overdue.

We have to admit that engineering advance, in the face of such difficulties as that of fatigue, has been gained largely by the application of what might be called the classical principles of design. More and more ingenuity has been required as the operating conditions have increased in severity, and some short relief has been obtained by the development of new high-temperature high-strength alloys. On the whole, the traditional methods of testing, coupled with established principles of stress relief, have enabled technological practice to keep up with the demands made upon it. There are, however, no large factors left in the equations. Even where some distinctive improvement in the properties of metals may be anticipated, it is quite certain that this will be quickly swallowed up by an immediate raising of design specifications. Fatigue, then, will always be with us. Supersonic machines, rockets and hightemperature gas turbines are already a reality, but their performance is below, well below, that required of them in the future. The conditions to which they will most certainly be subjected will not only be severe in themselves, but will also provide a combination of stress and temperature conditions under which fatigue, as a single factor, will be of no interest whatever. The important problem will be the survival of machines as a whole, under the complex working conditions imposed. This means their survival under repeated cycles of thermal shock, fatigue and creep, together with any other processes, such as corrosion, which may arise, the actual history being made up of both regular and random components. Although it is generally agreed that fullscale tests on major assemblies (such as aircraft) are here to stay, despite the cost, it seems worth remembering that in the case of high-speed flight the working conditions may not be reproducible at all in test form. 
We are, then, confronted with a situation which differs from the past not merely in the degree of the problems faced, but in their quite revolutionary nature as well. We now have to design for change in machines, knowing that they will change and knowing that they will fail. The material design no longer demands simply knowledge of a set of static factors, but requires information on dynamic processes with statistical characteristics. The traditional methods will certainly go on indefinitely fulfilling their purpose in many fields, and they will improve ; but if the materials barrier, as it may be called, is to be broken, a quite new philosophy of design is required. Whatever may develop in the future, it is certain that a mere scaling-up of the test resources, a continued amassing of data on individual properties, and a hand-to-mouth selection of material will be inadequate, however good the basic design may be. At present, not even the faintest framework of a solution exists ; but there is a growing awareness of the need for some part of science and engineering to concern itself with the possibilities of quite new methods of design, particularly in the selection of materials. Such studies cannot be made without getting well away from particular problems of detail and seeing the full implications of the changes as they affect the methors of testing, the nature of the test data, the extraction of empirical factors and the use of such factors in actual design. Complex testing, so far as both stress and temperature are concerned, seems likely to replace much of the single-property fixed-conditions testing at present undertaken. 'The assembly of the data into a suitable usable form is bound to be fraught with great difficulties. But computing and data-processing tech- niques have transformed similar situations elsewhere, and encourage hopes of some success in this direction as well.

We may sum up somewhat as follows. Fundamental science needs to order its ideas on the processes which occur in metals under alternating stresses, and to be more rigorous in the distinctions drawn between fatigue and other parallel processes. The theories, though superficially sound, are facile and lack the conviction which only critical experiment can give them. The bulk of applied work on fatigue continues very successfully, according to established principles, and one by one the numerous engineering factors are being run through. There is an improved agreement between different centres of research following the better design of test machines and the recognition of differences between them, but there is a real need for an infusion of statistical theory. For the future, engineering design needs to be supplemented (not replaced) by a quite different approach involving new and, at present, unknown methods, in which fatigue takes its place as one of several interacting processes which combine to bring about, inevitably, a failure of the machine.

Conferences on the scale of the one recently held in London involve a prodigious amount of work and planning, both technical and administrative, and something more than a formal acknowledgment to the bodies concerned is required. The quality of the organization does all concerned great credit, and due to their efforts a real and effective contribution has been made to the subject. The final proceedings, when published, will be on a scale quite unlike anything attempted previously, and will surely in time become established as a major work of reference.

\section{OBITUARY}

\section{Prof. John Garstang}

John Garstang was born in 1876 at Blackburn, where his father, Dr. Walter Garstang, was a wellknown physician. After leaving Blackburn Grammar School, he went to Jesus College, Oxford, with a mathematical scholarship, and graduated in 1899. While still an undergraduate his interest in archæology had been awakened, and from 1897 for some nine or ten years he undertook research and excavations at various sites of Roman Britain, particularly at Rib. chester, Melandra Castle, Richborough and Brough.

His first visit to Egypt was in the winter of 1900 , when he excavated at Mahasna and Bet Khallaf for the Egypt Research Account. In the following winter, supported by friends in Liverpool, he excavated on his own account in the same district. By this time he had been introduced to University circles in Liverpool, and in 1902 he was appointed honorary reader in Egyptian archæology in the University of Liverpool. During this and the following years Garstang campaigned tirelessly to stimulate interest in archæology in Liverpool. These were the years when the University was about to obtain its charter and his appeals were not ignored, for an influential group of Liverpool citizens was specially interested in ensuring that the new University should be established on broad lines. It was almost entirely due to his efforts that a sum of $£ 10,000$ was raised, and thus by 1904 premises had been secured, staff recruited, and the Liverpool Institute of Archæology was inaugurated. It was Garstang who conceived and planned the Institute, it was he who made it possible, he was its honorary secretary, and retained that office for more than forty years until the independent existence of the Institute ceased with its incorporation in the University School of Archæology and Oriental Studies. In 1907 he was appointed John Rankin professor of the methods and practice of archæology in the University of Liverpool, and held the chair until his retirement in 1941.

Although each year he did a certain amount of teaching and lecturing in Liverpool, his principal interest was in excavation. His energy was immense, and every year until 1914 saw him excavating at one or more sites in the Near East. The list of sites is formidakle : Beni Hasan (1902-4), Naqada, Hierakonpolis, Edfu (Hissaia) and Nubia (1904-6), Abydos $(1906-9)$, and Meroe in the Sudan $(1909-14)$. At Meroe he conducted the first excavations on the site and uncovered a very large section of the enormous city. Most of the results of these excavations are still unpublished; but sufficient of his records has survived to encourage the hope that in the near future it will be possible to publish reasonably full details of his results.

During these busy years Garstang found time in 1907 to make a journey of survey and exploration 